\title{
THE CORROSIVE EFFECTS OF ARTIFICIAL SALIVA ON CAST AND RAPID MANUFACTURE-PRODUCED COBALT CHROMIUM ALLOYS
}

Original Article Citation: Frank Alifui-Segbaya, Paul Foley, R.J. Williams, (2013) "The corrosive effects of artificial saliva on cast and rapid manufacture-produced cobalt chromium alloys", Rapid Prototyping Journal, Vol. 19 Iss: 2, pp.95 - 99

Article type: $\quad$ Research paper

DOI:

$10.1108 / 13552541311302941$

Publisher: $\quad$ Emerald Group Publishing Limited

\section{INTRODUCTION}

Computer Aided Design and Computer Aided Manufacture (CAD/CAM) has been increasingly introduced into dentistry (Miyazaki et al., 2009), mainly in the form of using milling to produce items by a subtractive method of manufacture. This method has seen wide application in treatment options involving crowns, inlays and fixed partial dentures. The term 'rapid manufacture' (RM) covers several technologies and is an additive method of construction whereby layers of an item are built and added one at a time during fabrication. This technique has been less widely adopted in dentistry but has so far been used, for example, in the production of non-metallic surgical guides (Vandenbroucke and Kruth, 2007) and, fixed partial denture alloy substructures (3T RPD Ltd., 2008) and is becoming more common. The method could also be used for the fabrication of cobalt-chromium (Co-Cr) removable partial denture (RPD) frameworks and titanium palatal plates (Bibb et al., 2006; Williams et al., 2006; Gao et al., 2009) 
Dental alloys for use in RM techniques are available and manufacturers state that the alloys are compliant with International Organisation for Standardisation (ISO) standards (3T RPD Ltd., 2008) allowing use in the oral cavity. However, few published data are available for academic reflection. Details of some mechanical properties are accessible (Vandenbroucke and Kruth, 2007) but none relate to commercially available RM alloy corrosion. Given a probable increase in the use of RM alloys it is vital that the biocompatibility of these alloys is fully understood. It is especially important because the RM process is digitally controlled, being a one-step laser forming technique whereas the traditional casting process adopts the 'lost wax' technique, which is fraught with processing variables for the manufacture of denture frameworks in the dental laboratory. The different processing methods could affect the inherent mechanical properties of alloys with a consequent influence on corrosion behaviour (Vandenbroucke and Kruth, 2007). Similarly, the surface condition of a dental alloy has been identified as one of the factors influencing the release of ions (Can et al., 2004). A highly polished surface has been shown to be harder, less susceptible to plaque accumulation and more resistant to corrosion than samples studied in the 'as cast' condition (Geurtsen, 2002).

The research described here seeks to compare the corrosion properties of an RM type 4 alloy, EOS SP2 (EOS GmbH, Electro Optical Systems, Robert-Stirling - Ring, 82152 Krailling, Munich, Germany) with a type 5 RPD dental casting alloy, Vitallium ${ }^{\circledR}$ casting alloy (Elephant Dental B.V., Verlengde Lagewag 10, 1628 PM Hoorn, The Netherlands) for in vitro ion release according to BS ISO 10271:2001. The alloys specimens from both alloys were finished in electrobrightened and highly polished surfaces. The manufacturer of EOS SP2 alloy gives the alloying constituents of the former in percentages as follows: Co 63.2, Cr 24.4, Mo 5.2, W 5.2 and Si 0.9. The 
manufacturer of Vitallium dental casting alloy states that the composition is Co 60.6, $\mathrm{Cr} 31.5, \mathrm{Mo} 6, \mathrm{Mn}, \mathrm{Si}, \mathrm{C}<1.0 \%$. Thus in terms of the main constituents, $\mathrm{Co}, \mathrm{Cr}$ and Mo the compositions of the two alloys are similar. Vitallium is routinely used for manufacturing RPD frameworks while EOS SP2 powdered alloy is currently used for the production of dental restorations such as metallic copings for ceramic veneers. It is designed to be formed into substructures in an EOSINT M270 Direct Metal Laser Sintering Machine (3T RPD Ltd., 2008; EOS e-Manufacturing Solutions, n.d.). No powdered alloy is currently offered specifically for RPD frameworks.

\section{MATERIALS AND METHODS}

Highly polished samples were prepared for comparison of the two alloys and manufacture processes. In addition, since it is common practice to leave the fitting surface of an RPD framework in an electrobrightened condition, additional tests were performed on samples prepared in such a state. Overall, specimens were prepared to simulate the preparation of cobalt-chromium denture frameworks for clinical cases. Thus, the two alloys, methods of processing and surface finishes were compared. There were four groups:

1. EOS SP2 Direct Metal Laser Sintering alloy, polished

2. EOS SP2 Direct Metal Laser Sintering alloy, electrobrightened

3. Vitallium cast alloy, polished

4. Vitallium cast alloy, electrobrightened. 
Specimens for corrosion tests were prepared in accordance with ISO 10271 specifications. The number of samples in each group is discussed later but was above the ISO standard requirement for all groups.

\section{Cast specimen production:}

A rectangular prismatic plate $(45.5 \mathrm{~mm} \times 10.5 \mathrm{~mm} \times 2 \mathrm{~mm})$ was designed on a PC using SolidWorks 3D CAD (Dassault Systèmes SolidWorks Corp., 300 Baker Avenue, Concord, MA 01742) software to eventually produce burnout patterns. CAD data was imported into an SLA 250/40 machine (3D Systems Headquarters, Rock Hill, SC 29730 USA) as a Standard Triangulation file where plates were built in WaterShed® XC 11122 (Somos DSM, 1122 St. Charles Street, Elgin, IL 60120, U.S.A.), a clear, near colourless, water-resistant resin. The patterns were carefully examined for porosity and dimensional accuracy before being sprued with $4 \mathrm{~mm}$ diameter wax and invested (2 per ring) in graphite-free, phosphate-bonded precision investment material for removable partial denture frameworks (Granisit $\circledast$ Investment Material \& Liquid, SILADENT, Dr. Böhme \& Schöps GmbH, Im Klei 26, D- 38644 Goslar, Germany) at a powder/liquid mixing ratio of 180 grams of powder to $27 \mathrm{ml}$ of expansion liquid. The investment muffles were heated gradually in a furnace and cast in a centrifugal casting machine with induction melt facilities. The muffles were left to bench cool, divested and blasted with aluminum oxide (Charpelin \& Jacobs Limited, No. 1 Four Seasons Crescent, Kimpton Road, Sutton, Surrey SM3 9QR) silica free blast grains with a grain size of $60-80 \mu \mathrm{m}$ and working pressure of 3 bars. Sprues were removed with carborundum disks and the test pieces smoothed with ceramic-bonded stones prior to electrobrightening or polishing. 
Direct Metal Laser Sintering specimen production:

A rectangular prismatic plate $(50 \mathrm{~mm} \times 20 \mathrm{~mm} \times 1.8 \mathrm{~mm})$ was designed on a PC using SolidWorks 3D CAD software. A slightly larger initial size of specimen than the cast specimens allowed reduction and thus elimination of any delamination or curling which may have occurred in the RM process. The CAD data described above was sent to Renishaw (New Mills, Wotton-Under-Edge, Gloucester GL12 8JR, UK) for test piece production in SP2 alloy by DMLS.

\section{Final Sample sizes}

Both cast and RM built pieces were prepared by removing at least $0.1 \mathrm{~mm}$ of material from the surfaces, as specified by the standard (BS ISO 10271:2001), using ceramicbonded stones. One group of specimens was electrobrightened and the other group was subsequently polished with abrasive rubber wheels before final polishing was performed with Co-Cr polishing paste (Bego, Bremer Goldschlägerei Wilh. Herbst GmbH \& Co. KG, Technologiepark Universität, Wilhelm-Herbst-Str. 1, D - 28359 Bremen, Germany).

The final size of each cast and DMLS samples was $42.5 \mathrm{~mm} \times 10 \mathrm{~mm} \times 1.5 \mathrm{~mm}$ and $43 \mathrm{~mm} \times 10 \mathrm{~mm} \times 1.35 \mathrm{~mm}$ giving a total surface area of $10.08 \mathrm{~cm}^{2}$ and $10.03 \mathrm{~cm}^{2}$ respectively. On the other hand, the final size of cast and DMLS electrobrightened specimens was $40 \mathrm{~mm} \times 10 \mathrm{~mm} \times 1 \mathrm{~mm}$ and $42 \mathrm{~mm} \times 10 \mathrm{~mm} \times 1.6 \mathrm{~mm}$ which totalled 9 $\mathrm{cm}^{2}$ and $10.06 \mathrm{~cm}^{2}$ respectively. All specimens were cleaned with steam and dried with oil-and water-free compressed air.

Five samples in each group were tested, following ISO instructions, apart from group 3 above which was made up of 4 samples only. Nevertheless this remains a number of samples beyond the ISO requirement (BS ISO 10271:2001). 
All specimens were ultrasonically cleaned separately in ethanol $(99.8+\%$ analysis Certified AR, Fisher Scientific UK Ltd Bishop Meadow Road, Loughborough, Leicestershire, LE11 5RG) for 2 minutes, rinsed with Optima-LCMS grade water (Fisher Scientific UK Ltd Bishop Meadow Road, Loughborough, Leicestershire, LE11 5RG) and dried with oil-free air. During each test, specimens were suspended with a nylon thread (Geis-Gerstorfer et al., 1991) and immersed completely in test tubes containing an artificial saliva solution of $0.1 \mathrm{M} \mathrm{NaCl}$ (analytical grade) and $0.1 \mathrm{M}$ lactic acid (analytical grade) with a $\mathrm{pH}$ of $2.3 \pm 0.1$, again in compliance with the ISO. The $\mathrm{pH}$ of the freshly prepared sample solutions was measured with Jenway $\mathrm{pH}(-2$ to 16) meter (Bibby Scientific Limited, Staffordshire ST15 0SA, U.K.) before immersion of samples and repeated on residual sample solutions after each elapsed time period - the $\mathrm{pH}$ remained virtually the same before and after immersion. The test tubes were sealed to prevent evaporation of solution and maintained at $37^{\circ} \mathrm{C}$ in a water bath for $1,4,7,14,21,28,35$ and 42 days thus performing a time dependence test (BS ISO/DIS 10271:2009). The volume of solution to surface area of each alloy was at a ratio of $1 \mathrm{ml}$ of solution per $1 \mathrm{~cm}^{2}$ of sample surface area as prescribed by the standard. For each specimen group, additional test tubes were used to hold two reference solutions $(0.1 \mathrm{M}$ saline lactic acid without immersed specimens at $10 \mathrm{ml}$ and $9 \mathrm{ml} \pm 0.1$ volumes) tightly sealed and maintained in parallel with the solutions containing the specimens until the elapsed period. After each time period, specimens were removed from test tubes with a plastic tong, rinsed with distilled water and placed into new test tubes with freshly prepared solution for subsequent repetition of the tests as described above.

Each sample solution was analysed quantitatively with flame atomic absorption spectrometer (FAAS) for cobalt (Co), chromium ( $\mathrm{Cr}$ ) and molybdenum (Mo) ions 
after day $1,4,7,14,21,28,35$, and 42 of sample immersion in the solution. Co, $\mathrm{Cr}$ and Mo are the major alloying elements of the alloys under test and the ion release of these elements only was studied. Calibration of the atomic absorption spectrometer was achieved with standard solutions. The sample solutions were analysed for these elements at a detection limit of one part per million. To determine substance loss after each time period, sample solutions were shaken on an MS2 Minishaker (IKA-Werke GmbH \& Co. KG, D-79219, Staufen) before aspirated directly into a flame solaar 969 atomic absorption spectrometer (AAS) (Unicam Limited, York Street, Cambridge, CB1 2SX, U.K.). Triplicate absorbance readings per element in each sample solution were made and these readings were used to determine the mean concentration of the different elements ( $\mathrm{Co}, \mathrm{Cr}$ and $\mathrm{Mo})$ in parts per million (ppm). An average of $8 \mathrm{ml}$ of sample solution was enough for analysing the concentration of the three elements in each test tube. The reference solutions which served as blanks were used to establish the impurity level for each element of interest in the sample solution.

\section{RESULTS}

Table 1 shows the wavelengths at which the elements were detected with the atomic absorption spectrometer and the correlation of determination ( $R^{2}$ value) of the calibration curve of the elements. The calibration curves were used to determine the concentrations of the unknown quantities in the analytes by comparing them to the known quantities in the standard solutions (Harris, 2010). In Table 2, the sum of CoCr-Mo released and the mean corrosion rate $\left(\mu \mathrm{g} / \mathrm{cm}^{2 *} 42\right.$ days) after 42 days are shown. 
Table 1 showing the AAS Parameters for Elemental Release Analysis*

Correlation of determination of calibration curves

$\begin{array}{cccccccccc}\text { Element } & \text { Wavelength } & \text { Day 1 } & \text { Day 4 } & \text { Day 7 } & \text { Day } & \text { Day } & \text { Day } & \text { Day } & \text { Day } \\ & \text { (nm) } & & & & \mathbf{1 4} & \mathbf{2 1} & \mathbf{2 8} & \mathbf{3 5} & \mathbf{4 2} \\ \text { Cobalt } & 240.7 & 0.9996 & 0.9972 & 0.9971 & 0.9999 & 0.9995 & 0.9998 & 0.9999 & 0.9999 \\ \text { Chromium } & 357.9 & 0.9994 & 0.9992 & 0.9998 & 0.9998 & 0.9989 & 0.9993 & 0.9989 & 0.9996 \\ \text { Molybdenum } & 313.3 & 0.9702 & 0.9839 & 0.9796 & 0.9918 & 0.9921 & 0.9945 & 0.9877 & 0.9783\end{array}$

*All elements had a lower detection limit of one part per million (ppm) and required a linear calibration equation

Table 2 showing the elemental release after 42 days

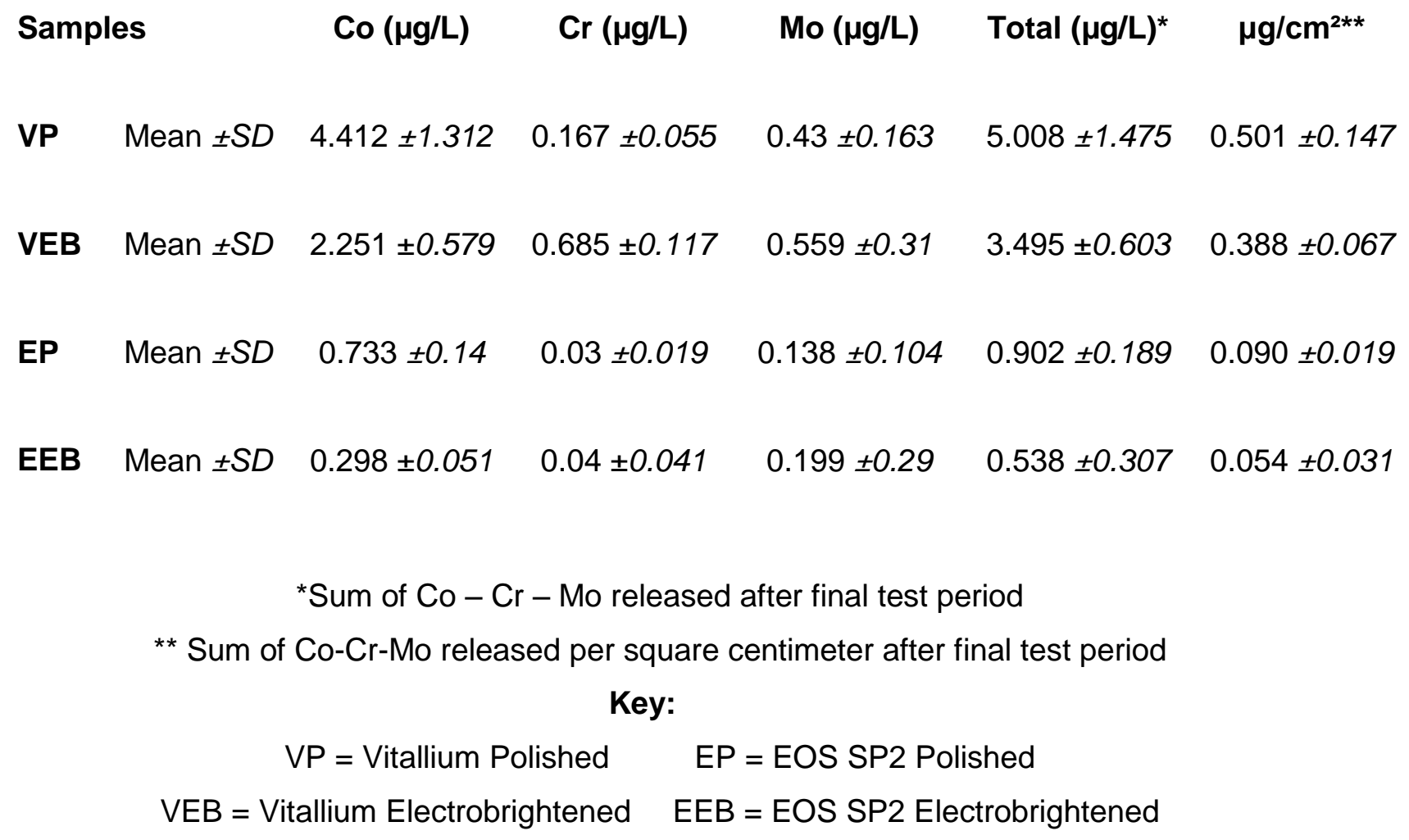




\section{Corrosion Test Graphs}

The line charts in the graphs show the corrosion trend over time, i.e. the mean release rate of each element with time. Elapsed time on the $\mathrm{x}$-axis is plotted against the release rate per day on the y-axis. Figure 1 shows the corrosion trends and the sum of all the elements released per day from VP and VEB samples and, EP and EEB samples in artificial saliva solution respectively. Figure 3 compares the four corrosion trends and the sum of all the elements released per day.

Graphs showing the amount of element released per day

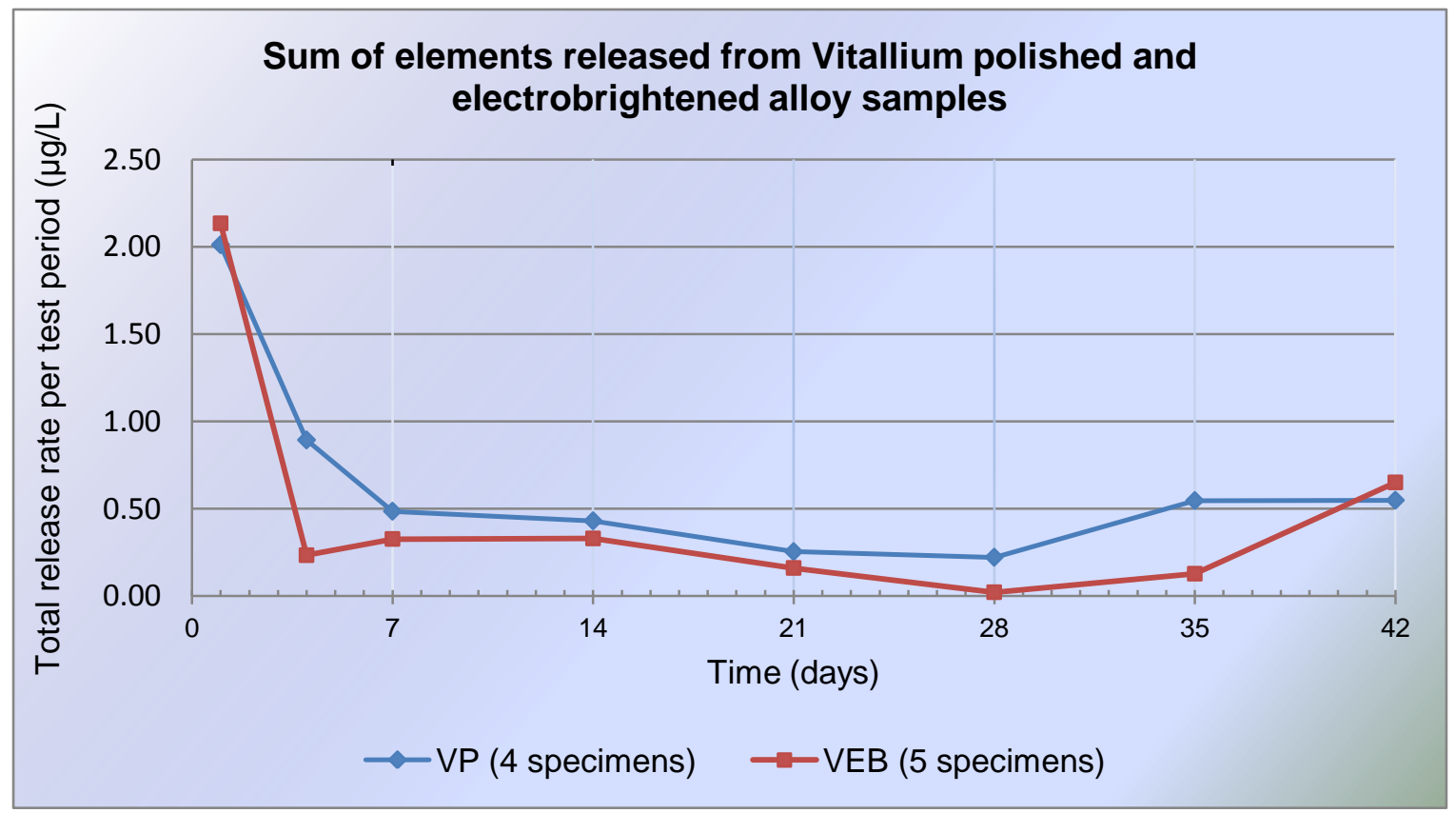

Figure 1: Corrosion trends of VP and VEB samples in artificial saliva solution 


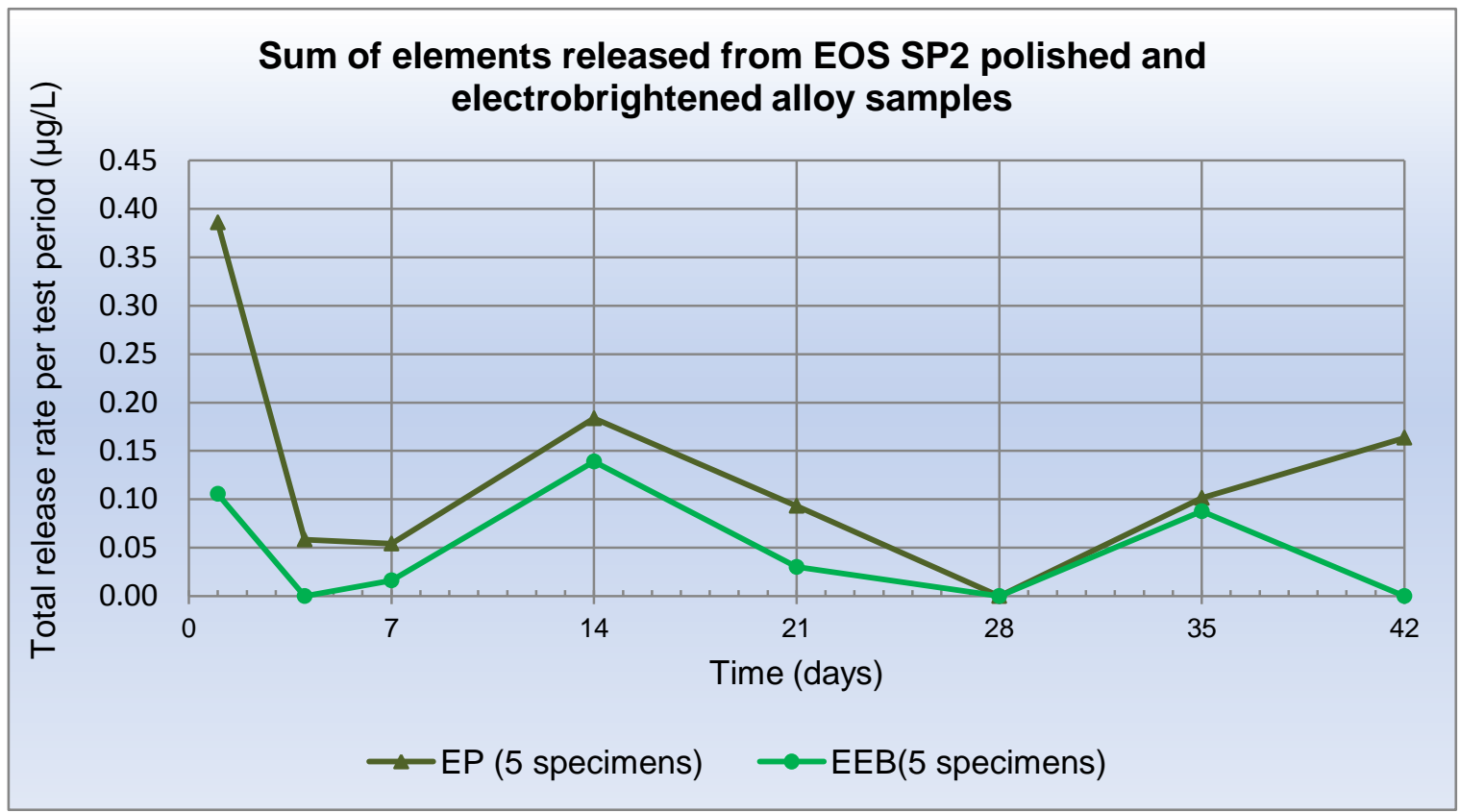

Figure 2: Corrosion trends of EP and EEB samples in artificial saliva solution

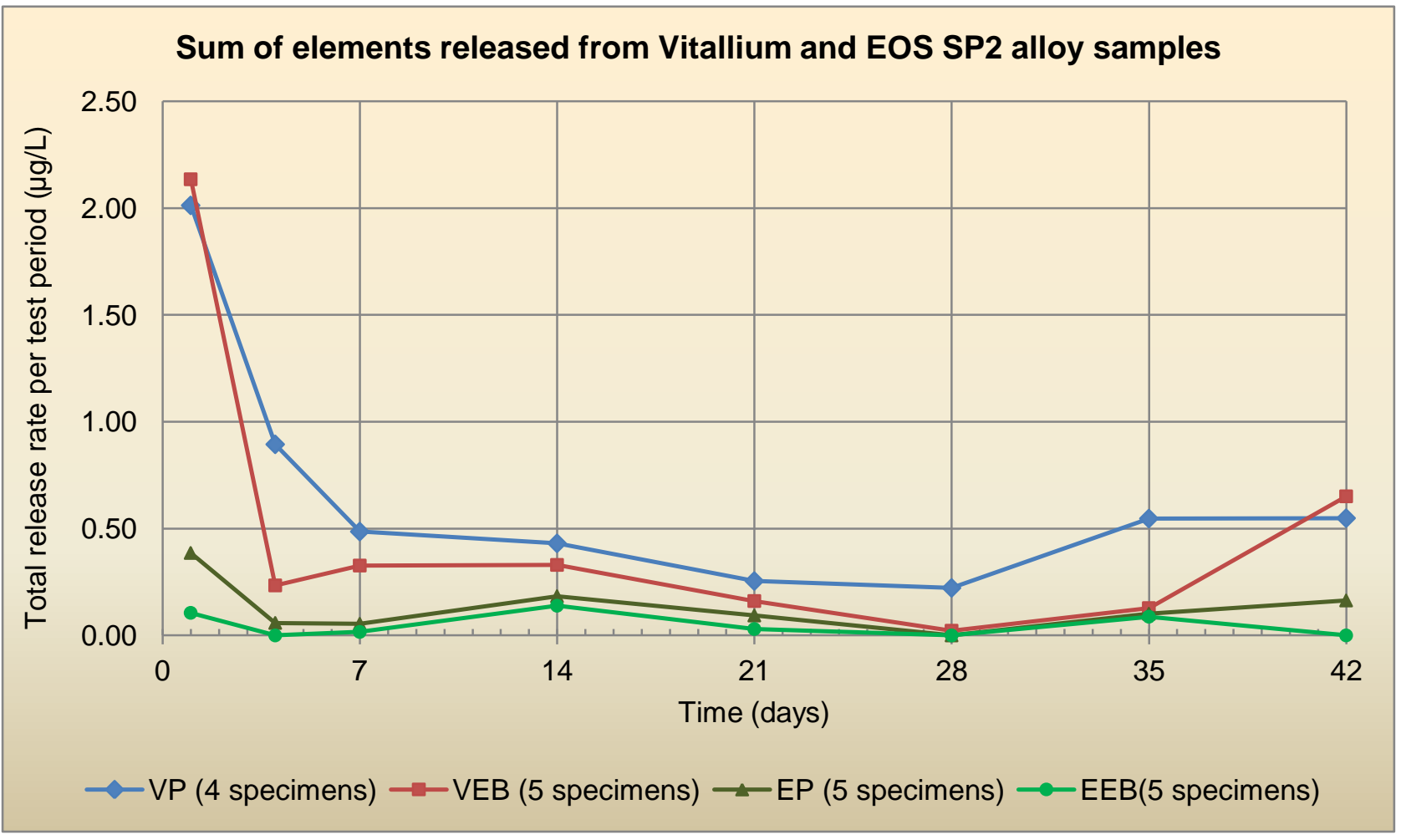

Figure 3: Corrosion trends of VP, VEB, EP and EEB samples in artificial saliva solution 
A three-way ANOVA and t-test $(\mathrm{P} \leq 0.01)$ for polished and electrobrightened samples were used. A three-way ANOVA test analysed the effect of time in days, alloy and surface finishes and the interaction between these variables on electrobrightened and polished samples. The results showed that there was a main effect of time $[F(1,1)=30.948, P<.01]$ and alloy, $[F(1,150)=103.600, P<.01]$. There was also a significant interaction between these factors, $[F(1,15)=20.072, P<.01]$. A follow up t-test was conducted to clarify the ANOVA results which indicated only the difference between groups. A t-test was used to compare the mean values of polished and electrobrightened samples of both alloys to help identify statistical significance in their total Co, Cr, Mo and sum of all the elements released after 42 days. The results obtained for comparing VP with EP samples and VEB with EEB samples showed that the release of $\mathrm{Co}, \mathrm{Cr}$ and the sum of all the elements for the two groups was statistically significant.

\section{DISCUSSION}

Tables 2 shows that the alloys are well below the allowable threshold limit of ion release prescribed by the standard, which is $200 \mu \mathrm{g}$ per square centimetre of $10 \mathrm{~cm}^{2}$ surface area for a test period of 7 days (BS ISO 22674:2006). The highest release

recorded in the study was just over $0.5 \mu \mathrm{g} / \mathrm{cm}^{2}$ for the VP group. The first and second graphs show a fairly sharp initial decrease in ion release with time and then a slight increase towards the end of the period of study. The third and fourth graphs appear to show a somewhat erratic release of ions. Both of these phenomena could be due to the fact that the readings obtained were at the lower limit of detection of 
the apparatus used. The equipment was not designed for obtaining data below $1 \mathrm{ppm}$.

The average substance loss per day from VP and VEB samples was $0.5 \mu \mathrm{g} / \mathrm{cm}^{2}$ and $0.39 \mu \mathrm{g} / \mathrm{cm}^{2}$ respectively. Those released from EP and EEB samples were 0.09 $\mu \mathrm{g} / \mathrm{cm}^{2}$ and $0.05 \mu \mathrm{g} / \mathrm{cm}^{2}$ respectively. In a study (Geis-Gerstorfer et al., 1991), figures that ranged from 0.43 to $34.9 \mu \mathrm{g} / \mathrm{cm}^{2}$ after 35 days of different Co-Cr alloy immersion in a similar solution was reported. Another study (Yfantis et al., 2007) reported $0.070 \mu \mathrm{g} / \mathrm{d} . \mathrm{cm}^{2}$ as the average total substance loss per day from polished Co-Cr alloy samples after 28 days of immersion. In this study a low $\mathrm{Cr}$ ion release was recorded. This is identical to trends seen in previous studies (Can et al., 2004; Yfantis et al., 2007; Al-Hiyasat et al., 2002).

Although RM alloys are similar in composition to traditional casting alloys, it is vitally important to subject RM-produced alloy to scrutiny to provide assurance that the new method of processing does not produce a dental device which is potentially hazardous to the patient. In the assessment of the biocompatibility of $\mathrm{Co}-\mathrm{Cr}$ alloys, ion release provides 'in vitro' data forming an excellent adjunct to cytotoxicity studies (Jevremović et al., 2011). The latter tend to analyse the reaction of cells which are found within the oral cavity whilst a study of ion release can give a good indication of whether any systemic clinical consequences are likely to occur. For example, cobalt deposits have been found to accumulate in the gut (Sternberg, 1982). The two prepared finishes were carried out to simulate the preparation of cobalt-chromium denture frameworks for clinical cases. The results shown above indicate that ion release from both alloys given the two different surface treatments is well within the threshold prescribed by the ISO and therefore, as far as corrosion defined according to the ISO standard is concerned, the greatest proportion of the alloy (Co, $\mathrm{Cr}$ and 
Mo) can be regarded as safe. It is also clear that the trend for both alloys and both surfaces over time is towards an increasing passivity.

The casting alloy studied is a type 5 dental casting alloy and the RM alloy is a type 4 . However, superior corrosion resistant qualities were evident in the latter. The Vitallium alloy has a higher composition of $\mathrm{Cr}$ and Mo than the EOS SP2 alloy yet the latter alloy displayed less susceptibility to corrosion attack. The increased corrosion resistance of the EOS SP2 alloy could be due to the addition of tungsten (W), which is known to improve the corrosion properties of $\mathrm{Co}-\mathrm{Cr}$ alloys and reduces chromium depleted inter-metallic areas (Roach, 2007). Multiple aspects of casting, including the length of cooling time whist the muffle is in the casting machine, the point at which the molten alloy is cast and the speed of the casting machine may influence ion release. These processes are difficult to control in a research setting, let alone in a production context. The RM process on the other hand is controlled digitally and thus offers a standard method for the production of dental items which is likely to be much closer to the manufacturer's specification than cast alloys and could be the reason for the improved performance of the RM alloy. A superior homogeneity of the EOS SP2 alloy manufactured by a laser melt technique is probable (Vandenbroucke and Kruth, 2007).

Perhaps in the abstract it could be expected that a greater passivity would result where surfaces are brought to a high lustre polish. However, it is interesting to note from the above results that there was no discernable difference between an electrobrightened surface and a highly polished surface for both alloys. 


\section{CONCLUSION}

The alloys studied showed a safe level of ion release for $\mathrm{Co}, \mathrm{Cr}$ and Mo according to the ISO definition. The elements studied make up well over $90 \%$ of the alloys. The RM-produced alloy performed better than the cast alloy. Data also indicated that there was no statistically significant difference in the corrosion properties of highly polished surfaces and electrobrightened surfaces.

\section{ACKNOWLEDGEMENT}

The authors are greatly indebted to Renishaw, New Mills, Gloucester, for kindly supplying the RM samples and to Dr Dominic Eggbeer, UWIC, for supplying resin samples for casting.

\section{REFERENCES}

1. 3T RPD Ltd. (2008), "Cobalt-Chrome Alloy", available at: www.3trpd.co.uk/pdf/Dental\%20Cobalt\%20Chrome\%20alloy\%20 (accessed 25 February, 2011)

2. 3T RPD Ltd. (2008), "Dental - 3T Frameworks", available at: http://www.3trpd.co.uk/dmls/dental-3t-frameworks.htm (accessed 19 May, 2010).

3. Al-Hiyasat, A.S., Bashabsheh, O.M. and Darmani, H. (2002), "Elements Released from Dental Casting Alloys and Their Cytotoxic Effects", The International Journal of Prosthodontics, Vol. 15, pp. 473-478. 
4. Bibb, R., Eggbeer, D. and William, R. (2006), "Rapid manufacture of removable partial denture frameworks", Rapid Prototyping Journal, Vol.12 Iss. 2, pp. 95-99.

5. British Standards Institute (2001), BS ISO 10271: Dental metallic materials Corrosion test methods, British Standards Institute, London.

6. British Standards Institute (2006), BS ISO 22674:2006: Dentistry - Metallic materials for fixed and removable restorations and appliances, British Standards Institute, London.

7. British Standards Institute (2009), BS ISO/DIS 10271: Dental metallic materials - Corrosion test methods, British Standards Institute, London.

8. Can, G., Akpinar, G. and Can, A. (2004), "Effects of Base-Metal Casting Alloys on Cytoskeletal Filaments in Cultured Human Fibroblasts", The International Journal of Prosthodontics, Vol. 17 No. 1, pp. 45-51.

9. EOS e-Manufacturing Solutions (n.d.), "Dentistry", available at: http://www.eos.info/en/applications/medical/dentistry.html (accessed 6 November, 2010)

10.Gao, B., Wu, J., Zhao, X. and Tan, H. (2009), "Fabricating titanium denture base plate by laser rapid forming", Rapid Prototyping Journal, Vol. 15 Iss. 2, pp. 133-136.

11. Geis-Gerstorfer, J., Sauer, K. and Passler, K. (1991), "Ion Release from NiCr-Mo and Co-Cr-Mo Casting Alloys", The International Journal of Prosthodontics, Vol. 4, pp. 152-158.

12. Geurtsen, W. (2002), "Biocompatibility of dental casting alloys, Critical Reviews in Oral Biology \& Medicine", Vol. 13 No. 1, pp. 74-84.

13.HARRIS, D.C. (2010), Quantitative Chemical Analysis (8th edn). W.H. Freeman and Company, New York, N.Y. 
14. Jevremović, D.P., Kojić, V., Bogdanović, G., Puškar, T., Eggbeer. D., Thomas, D. and Williams, R. (2011), "A selective laser melted Co-Cr alloy used for rapid manufacture of removable partial denture frameworks - initial screening of biocompatibility", Journal of the Serbian Chemical Society, Vol. 76 Iss. 1 , pp. $43-52$

15. Miyazaki, T. Yasuhiro, H., Kunii, J., Kuriyama, S. and Tamaki, Y. (2009), "A review of dental CAD/CAM: current status and future perspectives from 20 years of experience", Dental Materials, Vol. 28 No. 1, pp. 44-56.

16.Roach, M. (2007), "Base Metal Alloys Used for Dental Restorations and Implants", Dental Clinics of North America, Vol. 51 Iss. 3, pp. 603-627.

17. Sternberg, T. (1982), "Release of cobalt from cobalt chromium alloy constructions in the oral cavity", Scandinavian journal of dental research, Vol. 90, pp. 472-479.

18. Vandenbroucke, B. and Kruth, J.P. (2007) "Selective laser melting of biocompatible metals for rapid manufacturing of medical parts", Rapid Prototyping Journal, Vol. 13 Iss. 4, pp.196 - 203.

19. Williams, R.J., Bibb, R., Eggbeer, D. and Collis, J. (2006), "Use of CAD/CAM technology to fabricate a removable partial denture framework", Journal of Prosthetic Dentistry, Vol. 96 Iss. 2, pp. 96-99.

20. Yfantis, C., Yfantis, D., Anastassopoulou, J. and Theophanides, T. (2007), "Analytical and Electrochemical Evaluation of the in vitro corrosion behaviour of Nickel-chrome and Cobalt-chrome casting alloys for metal-ceramic restorations", European Journal of Prosthodontics and Restorative Dentistry. 2007; Vol. 15 No. 1, pp. 33-40. 